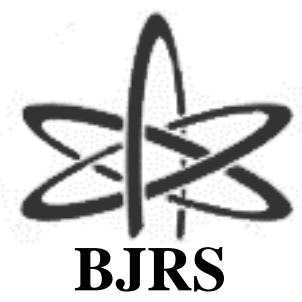

BRAZILIAN JOURNAL

$\mathrm{OF}$

RADIATION SCIENCES

07-02A (2019) 01-09

\title{
Diagnostic x-ray dosimeters using standard float zone (FZ) and XRA-50 commercial diodes
}

\author{
J. A. C. Gonçalves ${ }^{\mathrm{a}}$; V. S. M. Barros ${ }^{\mathrm{b}}$; V. K. Asfora ${ }^{\mathrm{b}}$; \\ H. J. Khoury ${ }^{b}$; C. C. Bueno ${ }^{\text {a }}$ \\ ${ }^{a}$ Instituto de Pesquisas Energéticas e Nucleares (IPEN-CNEN/SP) \\ 05508-000 São Paulo, SP, Brazil \\ josemary@ipen.br \\ ${ }^{b}$ Departamento de Física - Universidade Federal de Pernambuco (UFPE) \\ 50740-540 Recife-PE, Brazil
}

\begin{abstract}
The results obtained with a standard float zone (FZ) silicon diode, processed at the Helsinki Institute of Physics, used as on-line diagnostic X-ray dosimeter are described in this work. The device was connected in the short-circuit current mode to the input of an integrating electrometer. The response repeatability and the current sensitivity coefficient of the diode were measured with diagnostic X-ray beams in the range of $40-80 \mathrm{kV}$. The dose-response of the device, evaluated from $10 \mathrm{mGy}$ up to $500 \mathrm{mGy}$, was linear with high charge sensitivity. Nevertheless, significant energy dependence was observed in the charge sensitivity of FZ device for energies below $70 \mathrm{kV}$. The dosimetric characteristics of this FZ diode were compared to those of an XRA-50 commercial Si diode, specially designed to X-ray dosimetry. The results obtained with the FZ diode evidenced that it can be an alternative choice for diagnostic X-ray dosimetry, although it needs to be calibrated for individual X-ray beam energies. The studies of long-term stability and the radiation hardness of these diodes are under way.
\end{abstract}

Keywords: X-ray dosimetry, Si photodiodes dosimeters, Solid-state dosimetry.

ISSN: 2319-0612

Accept Submission: 2018-08-13 


\section{INTRODUCTION}

Semiconductor devices have been used for photon and electron beam dosimetry mainly in the field of radiation protection, medical imaging and radiation therapy [1-3]. One of the most important reasons in using semiconductor dosimeters is their higher sensitivity per unit of volume in comparison with ionization chambers. A precise measurement of the absorbed dose below a few ten ths of percent is required in the medical dosimetry. Use of $\mathrm{Si}$ devices demands a periodic recalibration of the dosimeter related to the sensitivity decay as a function of the accumulated dose. This drop in sensitivity due to radiation damage imposes constraint on the wides pread use of ordinary silicon diodes as dosimeters [4-7].

The drawback of the sensitivity drop is being overcome by the development of radiation tolerant silicon detectors in the framework of High Energy Physics research projects [8]. Previous results obtained in our laboratory using similar radiation-hard (rad-hard) Si diodes in radiation dosimetry $[9,10]$ motivated us to investigate the response of an n-type float zone (FZ) d iode for on-line diagnostic X-ray dosimetry. The rad-hard diode used was processed at the Helsinki Institute of Physics. The dosimetric characteristics of this FZ diode were compared to those of an XRA-50 commercial photodiode, specially designed for X-ray dosimetry [11].

\section{EXPERIMENTAL SETUP}

The radiation hard FZ diode had $\mathrm{p}^{+}-\mathrm{n}-\mathrm{n}^{+}$structure and thickness of $300 \mu \mathrm{m}$ with a sensitive area of $25 \mathrm{~mm}^{2}$. The XRA-50 PIN photodiode, manufactured by Detection Technology, had the same sensitive area of FZ diode $\left(25 \mathrm{~mm}^{2}\right)$ with an ultrafine entrance window. In order to use these diodes as dosimeters, they were housed in polymethylmethacrylate (PMMA) probes with $10 \mathrm{mg} / \mathrm{cm}^{2}$ thick paper windows.

Each device was directly connected in the photovoltaic mode to the input of a Keithley® $6517 \mathrm{~B}$ electrometer. The irradiation was performed with diagnostic X-ray equipment, with a total filtration of $2.5 \mathrm{~mm} \mathrm{Al}$. Measurements were carried out in air, with the diodes positioned at $1 \mathrm{~m}$ from the focus of the X-ray tube, using radiation field of $20 \mathrm{~cm} \times 20 \mathrm{~cm}$. The dose rate at this position was previously estimated using a calibrated ionization chamber Radcal 2026C. 
The response repeatability was evaluated for all energies by registering five consecutive current signals at the same radiation dose rate. The beam was switched on-and-off between measurements periods. At fixed voltages of $50 \mathrm{kV}$ and $80 \mathrm{kV}$, the output current signals from the diodes were registered as a function of the exposure time within the dose-rate range between $1.2 \mathrm{mGy} / \mathrm{min}$ to $42.8 \mathrm{mGy} / \mathrm{min}$.

The dose-response of the devices was investigated for doses from $10 \mathrm{mGy}$ to $500 \mathrm{mGy}$. The doseresponse is evaluated from the curves of charge as a function of the accumulated dose, where the charge is obtained by integrating the photocurrent signal over the measurement time. By changing the beam filtration and the bias voltage, the energy dependence of the diodes responses to 40, 50, 60,70 , and $80 \mathrm{kV}$ X-ray beams was evaluated.

\section{RESULTS AND DISCUSSIONS}

The dynamic current response of the rad-hard FZ diode and the commercial XRA-50 diode was investigated with irradiation energies of the X-ray beam from $40 \mathrm{kV}$ to $80 \mathrm{kV}$ and the dose rate range from $9.9 \mathrm{mGy} / \mathrm{min}$ to $42.8 \mathrm{mGy} / \mathrm{min}$. The results obtained with both devices evidenced that the current signals are very stable, as shown in Fig. 1, where five consecutive current signals of both diodes irradiated under $80 \mathrm{kV}$ X-ray irradiation and average dose-rate of $42.8 \mathrm{mGy} / \mathrm{min}$ are presented.

In addition, Fig. 1 shows a good repeatability of the diodes, characterized by a coefficient of variation of $0.1 \%$ and $0.2 \%$ for $\mathrm{FZ}$ and XRA-50 diodes, respectively. It is important to note that within the whole energy range, the output current signals were almost four orders of magnitude higher than the dark current of the diodes $\cong 3.6 \mathrm{pA}$ for $\mathrm{FZ}$ and $\cong 1.2 \mathrm{pA}$ for XRA-50), recorded after each measurement period when the beam was switched off.

For comparison, the average output current signals registered with FZ and XRA diodes irradiated with 50 and $80 \mathrm{kV}$ X-rays as a function of the dose-rate are depicted in Fig. 2. Within the dose rate range of $1.2 \mathrm{mGy} / \mathrm{min}$ up to $42.8 \mathrm{mGy} / \mathrm{min}$, the current responses of both diodes increased linearly with the dose-rate and no saturation of the current was observed. The corresponding values of the current sensitivity are presented in Table 1 . The energy dependence observed for the FZ diode might be caused by the non-ideal entrance window, compared to the very thin window of the XRA50 diode, for which no energy dependence was observed.

Figure 1: Current response of FZ and XRA-50 diodes under irradiation with $80 \mathrm{kVX}$-ray beam energy (dose-rate of $42.8 \mathrm{mGy} / \mathrm{min}$ ). 

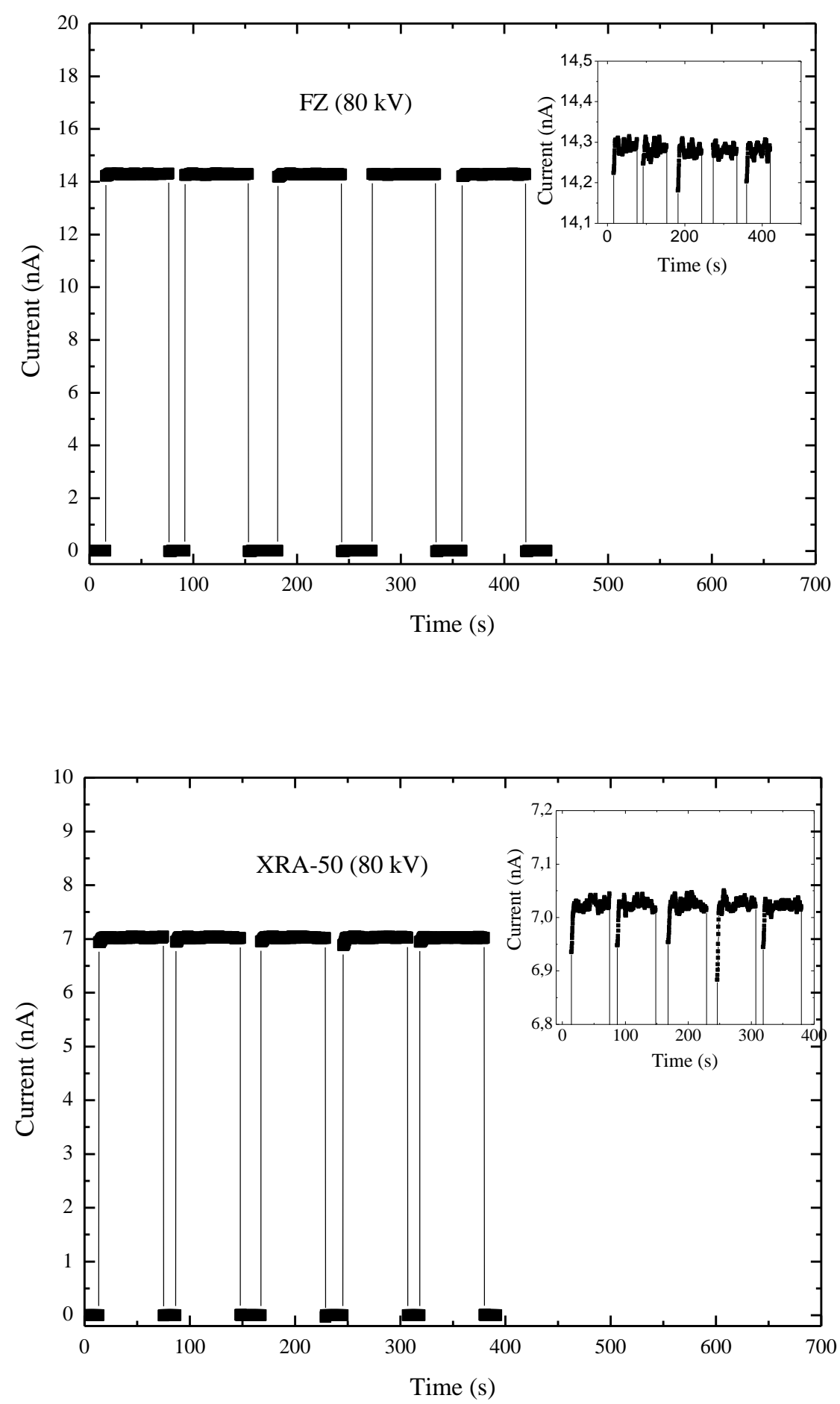

Figure 2: Current response of FZ and XRA-50 diodes as a function of the dose-rate for 50kV and $80 \mathrm{kV} X$-ray bias supply. 

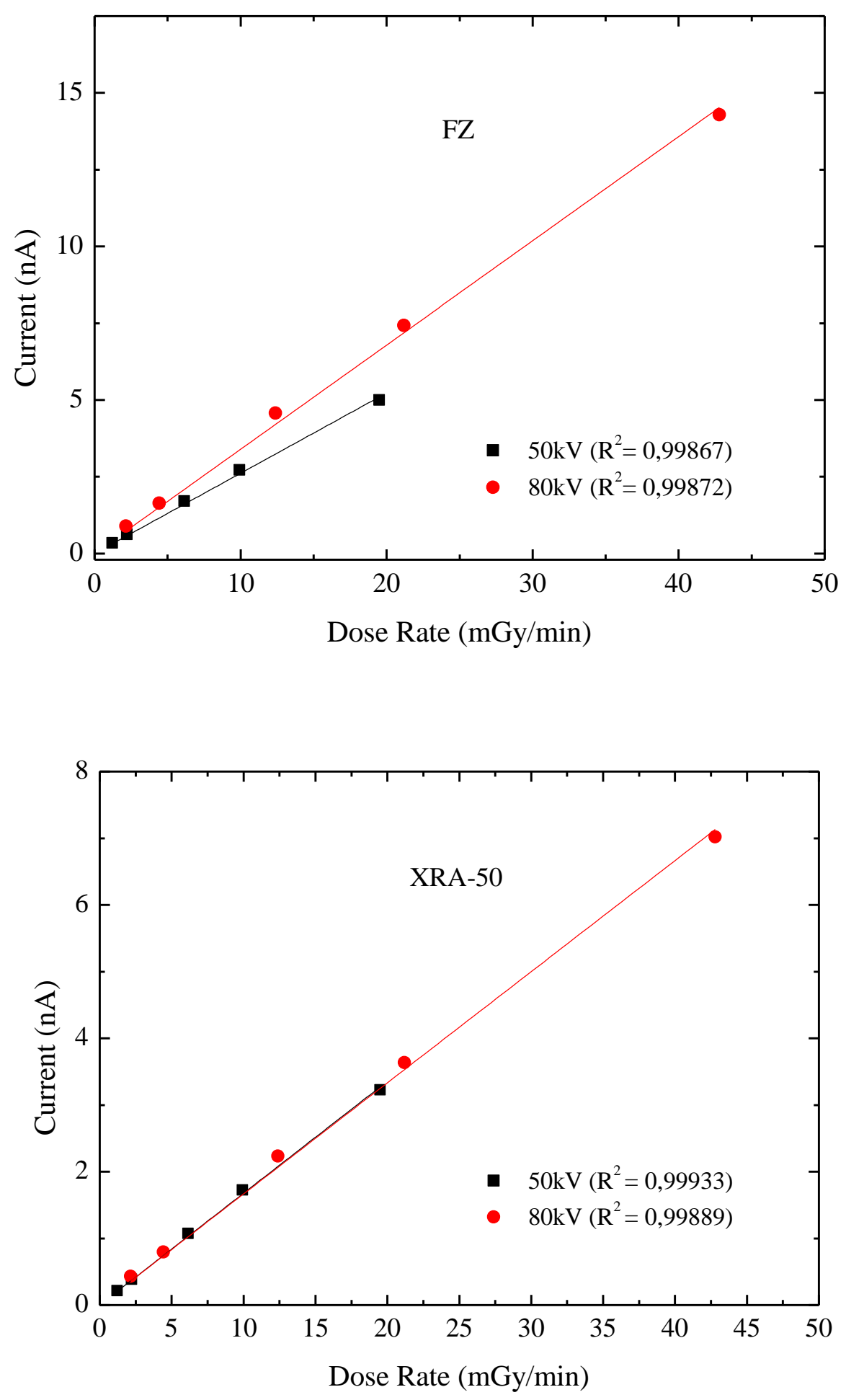

Table 1: Current sensitivity of FZ and XRA-50 diodes for $50 \mathrm{kV}$ and $80 \mathrm{kV}$ $\mathrm{X}$-ray bias supply. 


\begin{tabular}{|c|c|}
\hline $\begin{array}{l}\text { Energy } \\
(\mathrm{kV})\end{array}$ & $\begin{array}{l}\text { Current Sensitivity } \\
\text { (nA.min/mGy) }\end{array}$ \\
\hline \multicolumn{2}{|r|}{ c } \\
\hline 50 & $0.262 \pm 0.004$ \\
\hline 80 & $0.340 \pm 0.005$ \\
\hline \multicolumn{2}{|c|}{ XRA-50 } \\
\hline 50 & $0.167 \pm 0.002$ \\
\hline 80 & $0.166 \pm 0.003$ \\
\hline
\end{tabular}

The dose response of the diodes in the range of $10 \mathrm{mGy}$ and $500 \mathrm{mGy}$ is presented in Figs. 3 and 4, where the charge, obtained by integration of the current signal on a time interval of 60s, is plotted as a function of the accumulated dose. The results obtained with X-ray beam energies in the range of $40 \mathrm{kV}$ to $80 \mathrm{kV}$ confirm that the dose-response curves of both diodes are quite linear (coefficients of determination, $\mathrm{R}^{2}$, better than 0.99999 ) with high charge sensitivity. From these figures, it is also clear that the FZ diode exhibits a significant X-ray energy dependence for beam energies below 70 $\mathrm{kV}$, which might be attributed to the thickness of its entrance window. The correspondent charge sensitivities of the FZ and XRA-50 diodes are shown in Fig. 5 as a function of beam energies.

Figure 3: Dose-Response curves of the FZ diode for $40 \mathrm{kV}, 50 \mathrm{kV}, 60 \mathrm{kV}, 70 \mathrm{kV}$ and $80 \mathrm{kV}$ X-ray beam energy.

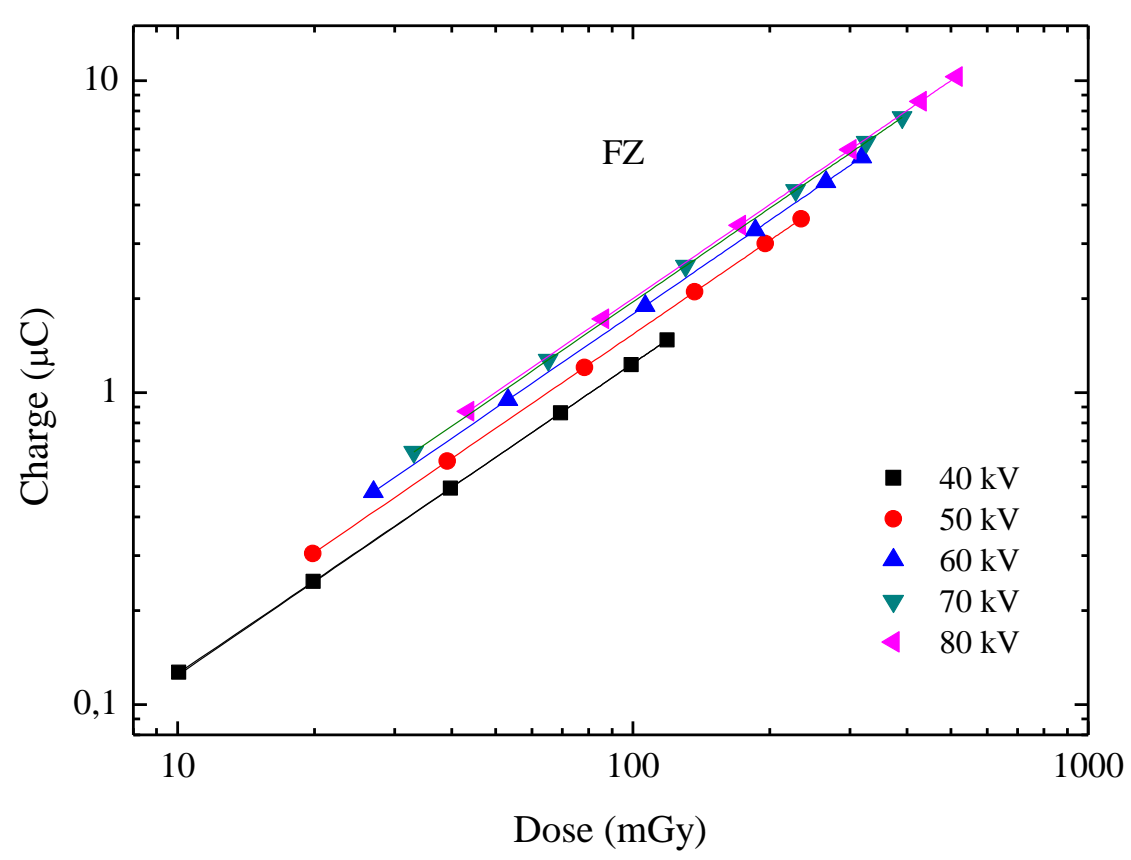

Figure 4: Dose-Response curves of the XRA-50 diode for $40 \mathrm{kV}, 50 \mathrm{kV}, 60 \mathrm{kV}, 70 \mathrm{kV}$ and $80 \mathrm{kV} X$ ray beam energy. 


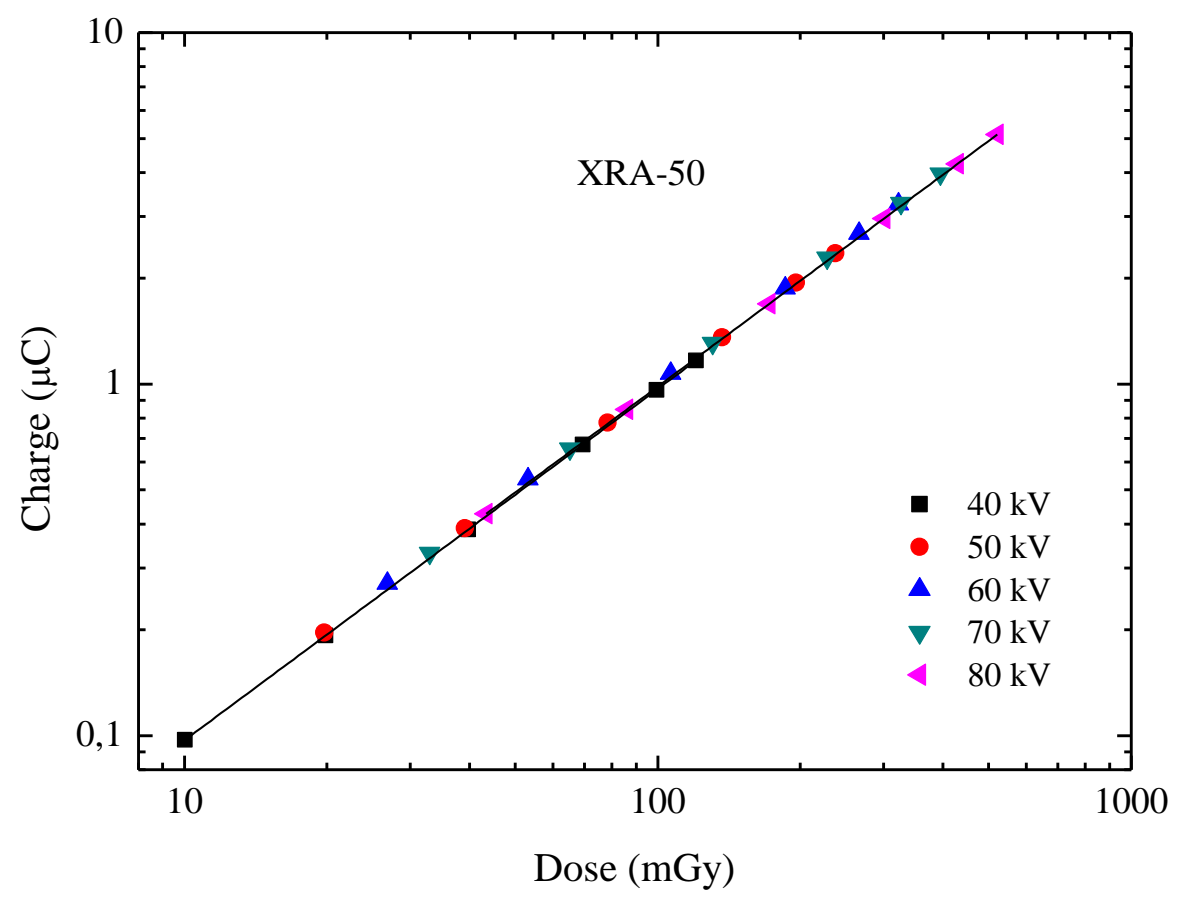

Figure 5: Charge sensitivity as a function of beam energies for FZ and XRA-50 diodes. The spline lines are only guide to the eyes.

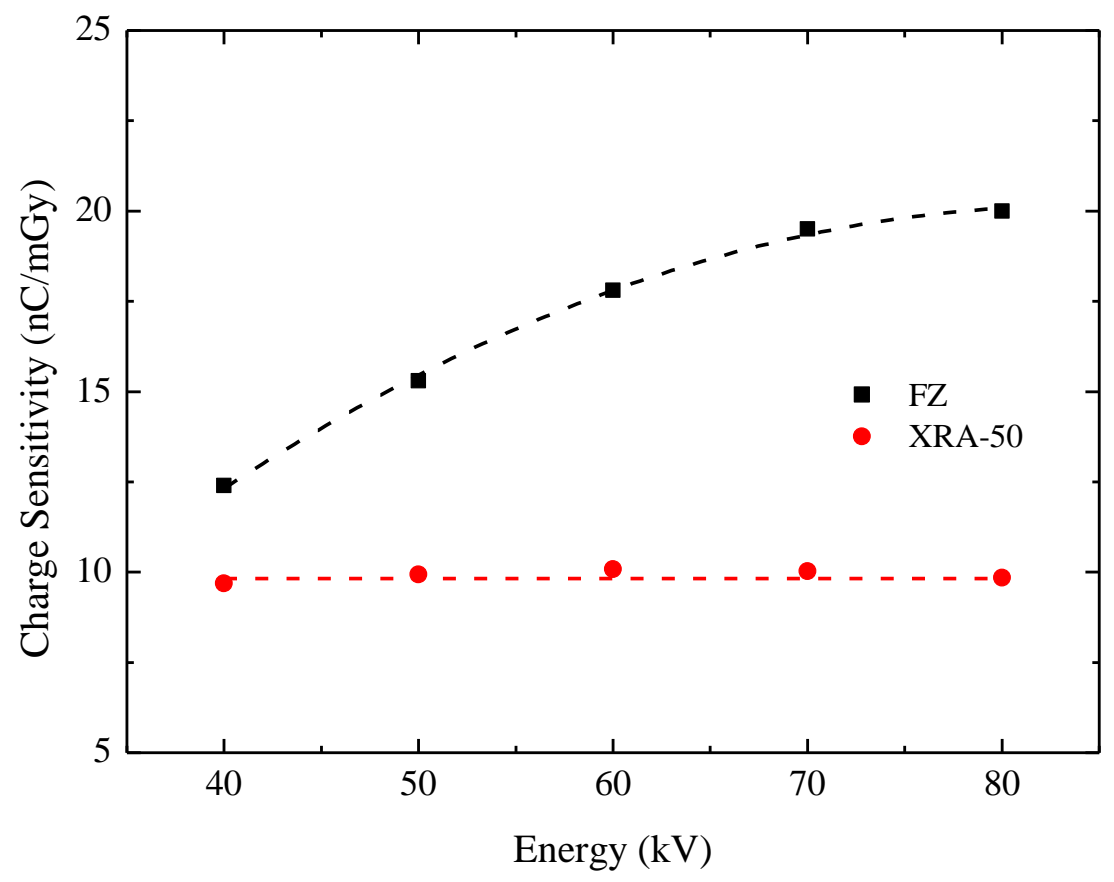

\section{CONCLUSION}


The dosimetric characteristics of a rad-hard FZ diode were investigated envisaging its application in on-line diagnostic X-ray beam dosimetry. The results obtained within the energy range of 40-80 kV were compared to those of a XRA-50 commercial Si diode. The dose-response of both devices, evaluated from $10 \mathrm{mGy}$ up to $500 \mathrm{mGy}$, was linear with high charge sensitivities ( $20 \mathrm{nC} / \mathrm{mGy}$ ). As expected from the radiation hardness of the FZ diode, studies related with the response repeatability confirmed that this device is more stable than the XRA-50 diode. Otherwise, due to the strong energy dependence, FZ diode needs to be calibrated separately for individual X-ray beam energies. The dosimetric performance of the FZ leads us to conclude that this device is a reliable alternative choice for diagnostic X-ray dosimetry. It worth noting that it remains to be investigated the longterm stability and the radiation hardness of these diodes for absorbed doses beyond the range investigated in this work. All these studies are under way.

\section{ACKNOWLEDGMENTS}

The collaboration of M. N. S. S. Magalhães from the Laboratório de Metrologia das Radiações Ionizantes - UFPE staff is highly acknowledged. This work was partially supported by CNPq under contracts 478967/2007-1 and 310493/2009-9.

\section{REFERENCES}

1. KHOURY, H. J.; HAZIN, C. A.; MASCARENHAS, A. P.; da SILVA Jr., E. F. Low cost silicon photodiode for electron dosimetry. Radiation Protection Dosimetry, v. 84, p. 341-343, 1999.

2. GRUSELL, E. and MEDIN, J. General characteristics of the use of silicon diode detectors for clinical dosimetry in proton beams. Phys. Med. Biol., v. 45, p. 2573-2582, 2000.

3. CASATI, M.; BRUZZI, M.; BUCCIOLINI, M.; MENICHELLI, D.; SCARINGELLA, M.; PIEMONTE, C.; FRETWURST, E. Characterization of standard and oxygenated float zone Si diodes under radiotherapy beams. Nucl. Instrum. Methods Phys. Res., Sect. A, v. 552, p. 158$162,2005$.

4. LINDSTROM, G.; MOLL, M.; FRETWURST, E. Radiation hardness of silicon detectors - a challenge from high-energy physics. Nucl. Instrum. Methods Phys. Res., Sect. A, v. 426, p. 1$15,1999$. 
5. CANDELORI, A. Radiation-hard detectors for very high luminosity colliders. Nucl. Instrum. Methods Phys. Res., Sect. A, v. 560, p. 103-107, 2006.

6. BOSISIO, L.; DITTONGO, S.; QUAI, E.; RACHEVSKAIA, I. Observation of substrate-type inversion in high-resistivity silicon structures irradiated with high-energy electrons. IEEE Trans. Nucl. Sci., v. 50, p. 219-22, 2003.

7. LI, Z.; LI, C. J.; VERBITSKAYA, E. Study of bulk damage in high resistivity silicon detectors irradiated by high dose of Co-60 gamma-radiation. IEEE Trans. Nucl. Sci., v. 44, p. 834-839, 1997.

8. HARKÖNEN, J.; ABERU, M.; ANBINDERIS, P.; ANBINDERIS, T.; D’AMBROSIO, N.; DE BOER, W., et.al. Recent results from the CERN RD39 collaboration on super-radiation hard cryogenic silicon detectors for LHC and LHC upgrade. Nucl. Instrum. Methods Phys. Res., Sect. A., v. 535, p. 384-388, 2004.

9. CAMARGO, F.; KHOURY, H. J.; NASCIMENTO, C. R.; ASFORA, V. K.; BUENO, C. C. Evaluation of a multi-guard ring (MGR) structure diode as diagnostic X-ray dosimeter. Nucl. Instrum. Methods Phys. Res., Sect. A, v. 580, p. 194-196, 2007.

10. CAMARGO, F.; GOnÇAlveS, J. A. C.; KHOURY, H. J.; NAPOLITANO, C. M.; HARKONEN, J.; BUENO, C. C. MCz diode response as a high-dose gamma radiation dosimeter. Radiat. Meas., v. 43, p. 1160-1162, 2008.

11. KHOURY, H. J.; SCHELIN, H.; SOBOLL, D.; LUNELLI, N.; BAPTISTA, C. Evaluation of commercial silicon diode for electron dosimetry. Nucl. Instrum. Methods Phys. Res., Sect. A, v. 580, p. 537-539, 2007. 